REVIEW

\title{
Can exercise improve self esteem in children and young people? A systematic review of randomised controlled trials
}

\author{
E Ekeland, F Heian, K B Hagen
}

Br J Sports Med 2005;39:792-798. doi: 10.1136/bjsm.2004.017707

A systematic review to determine if exercise alone or as part of a comprehensive intervention can improve self esteem in children and young people is described. Twenty three randomised controlled trials were analysed. A synthesis of several small, low quality trials indicates that exercise may have short term beneficial effects on self esteem in children and adolescents. However, high quality research on defined populations with adequate follow up is needed.

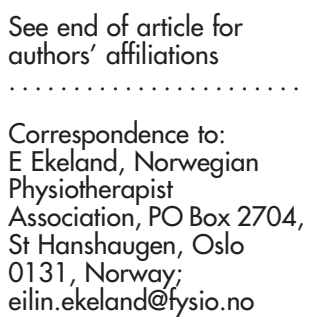

Accepted 6 June 2005
B etween $10 \%$ and $20 \%$ of children and adolescents have psychological and behavioural problems and about $7 \%$ need psychological treatment. ${ }^{2}$ Resilience research has led to an increasing awareness of positive factors in the environment, social relations, and individuals that protect against the development of problems..$^{3-5}$ Among individual qualities, self concept is one of the indicators given most attention. Self concept is defined as an "organised configuration of prescriptions of the self which are admissible to awareness" ${ }^{\prime 6}$ The evaluative component of self concept used in this article, self esteem, is "the degree to which individuals feel positive about themselves" ${ }^{6}$

Systematic reviews indicate a positive effect of physical activity on depression, anxiety, and behavioural problems in children and adolescents. $^{7-9}$ The effect of physical activity on self esteem in children has also been investigated, ${ }^{10}$ and one meta-analysis concluded that directed play and/or physical education programmes contributed to the development of self esteem in elementary school age children. ${ }^{11}$ This and other reviews have not been updated and lack description of systematic search and quality assessment of the included studies. ${ }^{89}$

The aim of this systematic review is to determine if exercise interventions can improve self esteem among children and young people.

\section{METHOD \\ Searching}

Searches were conducted in the Cochrane Controlled Trials Register (CENTRAL) (Issue 1, 2004), Medline (1966-2002), Embase (19822002), CINAHL (1982-2002), PsycINFO (18872002), and ERIC (1965-2002). The search terms were a wide range of terms about children and young people, physical activity, and self esteem. The complete search strategy is available in the original publication. ${ }^{12}$ The authors of included studies were contacted, and the Journal of the American Academy of Child and Adolescent Psychiatry was hand searched (1998-2002). There were no language restrictions.

\section{Selection}

Inclusion of studies was restricted to randomised controlled trials and "quasi-randomised" trialsthat is, a study that uses methods of allocation that are subject to bias in assignment, such as alternative allocation, case record numbers, dates of birth-with children from 3 years of age to young people up to 20 years old. Trials with children and young people with psychotic or borderline conditions, autism, physical handicap, eating disorders, and chronic somatic/physical diseases were excluded. The interventions had to be gross motor, energetic activity with minimum duration four weeks.

Two reviewers judged independently whether the studies fulfilled the inclusion criteria. If there was uncertainty or disagreement, a third reviewer was consulted.

\section{Validity assessment}

Two reviewers independently assigned these five quality criteria to each selected study: ${ }^{13}$

\section{(1) Concealment of allocation}

(2) Outcome assessment (assessor unaware of the assigned treatment when collecting outcome measures)

(3) Co-intervention (interventions other than exercises avoided, or used similarly across comparison groups)

(4) Losses to follow up

(5) Intention to treat

Uncertainty or disagreement was resolved by discussion with the third reviewer. Studies were then grouped as studies with a low risk of bias (all criteria met), studies with a moderate risk of bias (three to four criteria met), and studies with a high risk of bias (fewer than three criteria met). As there is no clear evidence that some criteria are more important than others, they were given equal weight.

Data extraction and study characteristics Each reviewer independently extracted data on population, age, baseline characteristics, characteristics of activity, compliance, and outcome measures. In cases of missing information, one author of the paper was contacted.

Abbreviations: SMD, standardised mean difference; $\mathrm{Cl}$, confidence interval 


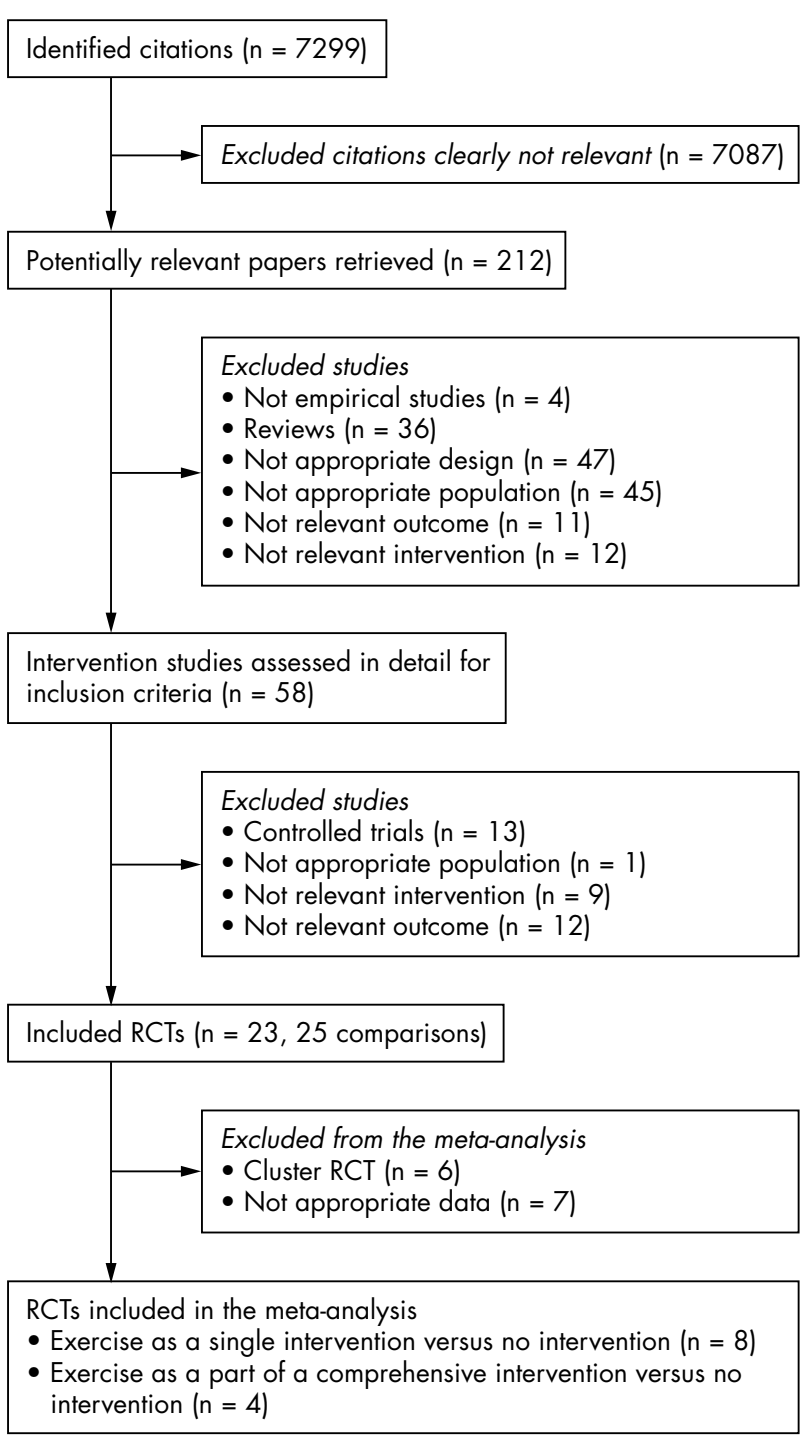

Figure 1 Selection of eligible randomised controlled trials (RCTs) from all identified citations.

\section{Quantitative data synthesis}

Self esteem was measured with similar, but not identical, instruments across studies, and standardised mean differences (SMDs) and 95\% confidence interval (CI) were calculated. The SMD expresses the size of the treatment effect in each trial relative to the variability observed in that trial. ${ }^{13}$ There was clinical heterogeneity between trials, with differences in study quality, the type or length of the intervention, and participant characteristics. Statistical heterogeneity was assessed using the $\chi^{2}$ test of heterogeneity along with a visual inspection of the graph. Such heterogeneity was identified. Overall effects were therefore calculated using a random effects model. When the primary studies provided several measures of self esteem, the overall self esteem score, often called global self esteem score in the papers, was used in the analysis. The effect sizes were translated back into clinically relevant values by using the $80 \mathrm{~mm}$ Piers-Harris children's self-concept scale. ${ }^{14}$ On the basis of data from one of the included studies, ${ }^{15}$ we used standard deviation (SD) of 11 points for this calculation. To further enlighten the interpretation of the effect magnitude, we calculated the percentage difference between control and intervention groups by using the back translated Piers-Harris scores and post-treatment value in the control group as the basis.

To assess the robustness of conclusions as to quality of data and clinical heterogeneity, sensitivity analyses were performed according to levels of methodological quality, the type or length of the intervention, and participant characteristics. In the protocol we also specified age, sex, and compliance as potential important variables in the sensitivity analyses. However, because of limited information in the included studies, it was not possible to explore further the influence of these variables.

None of the included cluster randomised studies provided data on intra-cluster correlation and could therefore not be included in the meta-analyses. For these and other trials that did not provide sufficient data to calculate overall effects, a qualitative summary was provided.

\section{RESULTS}

\section{Trial flow}

We identified 7299 citations, retrieved 212 potentially relevant papers, and assessed 58 in detail (fig 1). In the end, 23 were included. ${ }^{15-37}$ The excluded studies were those not randomised, with short term interventions, no gross motor activity, or without self esteem as the outcome measure.

\section{Study characteristics}

The included studies involved 24-288 participants aged 319.8 years. The participants were healthy, had learning disabilities and/or emotional disturbances, low self image, gross motor problems, or were young offenders. Most of the interventions lasted for 4-20 weeks, but one study had an intervention period of nine months. ${ }^{21}$ The interventions included aerobic, strength training, skills training, and combinations of these (tables 1 and 2). Two of the included studies $^{25}{ }^{28}$ compared two different interventions versus control, and the analysis therefore includes 25 comparisons.

Outcomes were measured at the end of the interventions, and no further follow up results were given for any of the studies. There was variation in the quality of the studies (table 3), and only one study met all five methodological criteria. ${ }^{16}$

\section{Synthesis of quantitative data}

From a clinical point of view, the context in which the physical activity was carried out may be of importance to the outcomes. We therefore differentiated between studies that focused on exercise only and studies explicitly focusing on skill training, counselling, the social setting, or other motivational factors as a part of the exercise intervention.

\section{Exercise as a single intervention versus no intervention}

This comparison included 13 studies (table 1) with eight in the meta-analysis (fig 2). The overall SMD was 0.49 (95\% CI 0.16 to 0.81 ) in favour of the exercise intervention. This corresponds to a difference of 5.4 points on a $0-80$ scale, or about a $10 \%$ difference between the intervention and the control group. The subtotals for the study with a low risk of bias showed a SMD of 1.33 (95\% CI 0.43 to 2.23), which corresponds to a difference of 14.6 points on the same scale. ${ }^{16}$ The studies with a moderate risk of bias showed a nonsignificant SMD of 0.21 (95\% CI -0.17 to 0.59 ), and the studies with a high risk of bias had a SMD of 0.57 (95\% CI 0.11 to 1.04). Five studies in this comparison were not included in the meta-analysis. Hilyer and Mitchell ${ }^{25}$ with high risk of bias found a significant improvement $(\mathrm{p}<0.01)$ for those with a low self concept at baseline. One study with a moderate risk of bias ${ }^{34}$ reported a significant effect $(\mathrm{p}=$ 
Table 1 Characteristics of randomised controlled trials comparing exercise as a single intervention with no intervention

\begin{tabular}{|c|c|c|c|}
\hline Study & Participants & Interventions & Duration \\
\hline Alpert $1990^{16}$ & 24 healthy boys and girls, aged 3-5 years & $\begin{array}{l}\text { I: Aerobic classroom activity with music. } \\
\text { HR } 60-80 \% \\
\text { C: Outdoor play }\end{array}$ & $30 \mathrm{~min}, 5$ times a week for 8 weeks \\
\hline Basile $1995^{17}$ & $\begin{array}{l}53 \text { boys and } 5 \text { girls from clinic (day treatment } \\
\text { for emotionally and behaviourally disturbed } \\
\text { children), aged } 7-13 \text { years }\end{array}$ & I: Jogging/walking & $20 \mathrm{~min}, 4$ times a week for 4 weeks \\
\hline Ford $1989^{22}$ & 97 healthy girls, mean age 19.8 years & $\begin{array}{l}\text { C: Classroom activity } \\
\text { I: Jogging, swimming or dance for fitness, } \\
\text { or weight training } \\
\text { C: Health science }\end{array}$ & 3 hours a week for 8 weeks \\
\hline Herman-Tofler $1998^{23}$ & 52 healthy 3 rd grade students & $\begin{array}{l}\text { I: Aerobics } 60-85 \% \mathrm{VO}_{2} \max \\
\text { C: Traditional physical education, } \\
\text { not aerobic }\end{array}$ & 25 min, 3 times a week for 8 weeks \\
\hline Hilyer $1979^{25}$ & 120 students, mean age 19.1 years & $\begin{array}{l}\text { I: Running } \\
\text { C: Ordinary classes }\end{array}$ & $60 \mathrm{~min}, 3$ times a week for 10 weeks \\
\hline MacMahon $1987^{27}$ & $\begin{array}{l}54 \text { children with learning disabilities but } \\
\text { normal WISC-R, aged } 7.1-12.75 \text { years }\end{array}$ & $\begin{array}{l}\text { I: Distance running, aerobic dance, } \\
\text { and soccer, HR }>160 \\
\text { C: Maze patterns, dodge ball, volleyball, } \\
\mathrm{HR}<150\end{array}$ & $25 \mathrm{~min}, 5$ times a week for 20 weeks \\
\hline MacMahon $1988^{15}$ & $\begin{array}{l}98 \text { boys from juvenile detention facilities, } \\
\text { aged } 14-18 \text { years }\end{array}$ & $\begin{array}{l}\text { I: Long distance running and vigorous } \\
\text { basketball, } H R>160 \\
\text { C: Less vigorous activity; baseball, } \\
\text { volleyball, etc, } \mathrm{HR}<160\end{array}$ & 40 min, 3 times a week for 3 months \\
\hline Marsh $1988^{28}$ & 137 girls, aged $11-14$ years & $\begin{array}{l}\text { I: Aerobics, competitive with individual } \\
\text { training } \\
\text { C: Social volleyball game }\end{array}$ & $35 \mathrm{~min}, 14$ times during 6 weeks \\
\hline Munson $1988^{31}$ & $\begin{array}{l}26 \text { offenders from a security institution, } \\
\text { mean age } 17.2 \text { years }\end{array}$ & $\begin{array}{l}\text { I: Strength training, frisbee, golf, } \\
\text { volleyball, basketball, etc } \\
\text { C: Discussions }\end{array}$ & 1 hour a week for 10 weeks \\
\hline Percy $1981^{32}$ & 30 healthy fifth and sixth grade pupils & $\begin{array}{l}\text { I: Running } \\
\text { C: No intervention }\end{array}$ & $\begin{array}{l}1 \text { mile, } 3 \text { times a week for } 7 \text { weeks } \\
\text { Decided when to run themselves }\end{array}$ \\
\hline Salokun $1994^{34}$ & 288 healthy young people, aged $12-18$ years & $\begin{array}{l}\text { I: Field hockey (96), sprint (32), } \\
\text { discus (32), or long jump (32) } \\
\text { C: No skill training }\end{array}$ & $45 \mathrm{~min}, 3$ times a week for 10 weeks \\
\hline Smith $1984^{36}$ & 32 healthy pupils, fourth and fifth grade & $\begin{array}{l}\text { I: Progressive running } \\
\text { C: Ordinary PE class }\end{array}$ & 10 weeks \\
\hline Tuckman $1986^{37}$ & 154 healthy pupils, fourth to sixth grades & $\begin{array}{l}\text { I: Running } \\
\text { C: Ordinary PE class }\end{array}$ & $30 \mathrm{~min}, 3$ times a week for 12 weeks \\
\hline
\end{tabular}

$0.05)$, whereas one with moderate risk of bias, ${ }^{37}$ and two with high risk of bias ${ }^{17}{ }^{28}$ reported no significant effect.

The sensitivity analysis showed that the effect size was not significant when the studies of healthy children were analysed separately. There were little or no differences when we analysed the results without the strength training studies or excluded the studies with interventions less than 10 weeks or with great baseline differences.

\section{Exercise as a part of a comprehensive intervention versus no intervention}

This group of interventions included 12 studies (table 2), with only four in the meta-analysis (fig 3 ). The results show an overall SMD of 0.51 ( $95 \%$ CI 0.15 to 0.88$)$, which corresponds to a difference of 5.6 points on a $0-80$ scale, or about a $10 \%$ difference between the intervention and the control group. No studies in this group had a low risk of bias, but in studies with a moderate risk of bias the SMD was nonsignificant at $0.32(95 \%$ CI -0.11 to 0.74$)$, and in those with a high risk of bias, the SMD was 0.76 (95\% CI 0.12 to 1.40 ). Studies not included in the meta-analysis all had a high risk of bias. Four studies ${ }^{19212533}$ found a significant treatment effect, and four ${ }^{20} 262829$ did not.

In this comparison, it was not possible to categorise the interventions, and no studies had interventions less than 10 weeks. When the single study with healthy participants was excluded from the meta-analysis, ${ }^{35}$ the SMD increased to 0.64 (95\% CI 0.22 to 1.06) which corresponds to a difference of 7.3 points on a scale from $0-80$. When the study with obvious baseline differences in self esteem ${ }^{30}$ was excluded, there was no clear difference (SMD 0.55 (95\% CI 0.07 to $1.03))$.

\section{DISCUSSION}

The objective of this review was to determine if exercise interventions can improve self esteem in children and young people. The results, based on 25 comparisons with participants aged 3-20 years, indicate that exercise can improve self esteem. This compares well with the meta-analysis of Gruber. ${ }^{11}$

Only one of the included studies was assessed to have a low risk of bias, and eight were categorised as studies with a moderate risk of bias. The remaining 14 studies had a high risk of bias. With these different methodological weaknesses in the studies, the analyses were carried out by categorising studies into three quality levels. In addition, the studies are grouped into two main comparisons, one where the intervention focus was exercise only (13 studies) and one where the exercise was combined with skills training, counselling, or social aspects (12 studies).

Because of cluster randomisation or insufficient data to calculate effect sizes, meta-analysis could be carried out for only 12 studies, eight that looked at exercise only and four that looked at exercise combined with other aspects. Both of these meta-analyses show a small overall significant treatment effect, corresponding to a difference of 5.4 and 5.6 points on a $0-80$ scale, or about a $10 \%$ difference between the intervention and the control group. Of the studies not included in the meta-analysis, seven showed a significant treatment effect and six did not. 
Table 2 Characteristics of randomised controlled trials comparing exercise as a part of a comprehensive intervention with no intervention

\begin{tabular}{|c|c|c|c|}
\hline Study & Participants & Interventions & Duration \\
\hline Bluechardt $1994^{18}$ & $\begin{array}{l}45 \text { pupils with learning } \\
\text { disabilities but normal WISC-R, } \\
\text { aged } 8.3-10.5 \text { years }\end{array}$ & $\begin{array}{l}\text { I: Pool and gymnastic activities, promoting skills } \\
\text { and developing social skills }\end{array}$ & $90 \mathrm{~min}$, twice a week for 10 weeks \\
\hline Boyd $1997^{19}$ & $\begin{array}{l}181 \text { healthy girls, } \\
\text { aged 9-16 years }\end{array}$ & $\begin{array}{l}\text { C: Assistance in deficient skills } \\
\text { I: "Package": Strength training, skipping, and running, } \\
\text { locomotor activities, education, and self reported } \\
\text { performance in log books } \\
\text { C: Regular PE classes }\end{array}$ & $\begin{array}{l}40 \text { min, } 9 \text { times for the youngest and } \\
12 \text { times for the older during } 6 \text { weeks }\end{array}$ \\
\hline Bruya $1977^{20}$ & $\begin{array}{l}72 \text { healthy pupils, } \\
\text { aged } 9-11 \text { years }\end{array}$ & I: Training basketball skills & 30 min, twice a week for 4 weeks \\
\hline Elstein $1977^{21}$ & $\begin{array}{l}33 \text { learning disabled } \\
\text { children with normal IQ, } \\
\text { aged } 7-15 \text { years }\end{array}$ & $\begin{array}{l}\text { C: No training } \\
\text { I (a): Basic motor and movement skills, balance, gymnastics, } \\
\text { physical fitness. Encouraged to extend themselves }\end{array}$ & 50 min, twice a week for 9 months \\
\hline & & $\begin{array}{l}\text { I (b): Skills in sports and ball games. Individual adjustment } \\
\text { C: Free play, a lot of equipment for activity available. } \\
\text { Child led activity }\end{array}$ & \\
\hline Hilyer $1979^{25}$ & $\begin{array}{l}120 \text { students, mean } \\
\text { age } 19.1 \text { years }\end{array}$ & I: Running with counselling & $60 \mathrm{~min}, 3$ times a week for 10 weeks \\
\hline Hilyer $1982^{24}$ & $\begin{array}{l}60 \text { adjudicated boys from a state } \\
\text { school, aged } 15.5-18.6 \text { years }\end{array}$ & $\begin{array}{l}\text { C: Ordinary classes } \\
\text { I: Brief meetings with goal setting, flexibility training, } \\
\text { weight training, run with gradual progress } \\
\text { C: Regular activity, team sport }\end{array}$ & 90 min, 3 times a week for 20 weeks \\
\hline Luebke $1977^{26}$ & 50 healthy third grade pupils & $\begin{array}{l}\text { I: Basic locomotor gymnastics, ball handling, dance, } \\
\text { rope-jumping skills } \\
\text { C: No instruction }\end{array}$ & $30 \mathrm{~min}$, twice a week for 13 weeks \\
\hline Marsh $1988^{28}$ & 137 girls, aged $11-14$ years & $\begin{array}{l}\text { I: Aerobics with cooperative training } \\
\text { C: Social volleyball game }\end{array}$ & $35 \mathrm{~min}, 14$ times during 6 weeks \\
\hline McGowan $1974^{29}$ & $\begin{array}{l}37 \text { seventh grade boys with } \\
\text { low self image and sociogram } \\
\text { score }\end{array}$ & $\begin{array}{l}\text { I: Success oriented endurance training (running and } \\
\text { competitive activities) }\end{array}$ & 3-4 times a week for 18 weeks \\
\hline Munson $1985^{30}$ & $\begin{array}{l}31 \text { boys from development } \\
\text { centre, aged } 14-18 \text { years }\end{array}$ & $\begin{array}{l}\text { C: Regular classes without PE classes } \\
\text { I: Strength training combined with leisure counselling } \\
\text { or combined with discussion } \\
\text { C: Regular institution programme }\end{array}$ & $90 \mathrm{~min}, 3$ times a week for 6 weeks \\
\hline Platzer $1976^{33}$ & $\begin{array}{l}40 \text { preschool children who } \\
\text { exhibited deficits in gross } \\
\text { motor skills and self concept, } \\
\text { aged } 35-72 \text { months }\end{array}$ & $\begin{array}{l}\text { I: Perceptual-motor training ensure success and } \\
\text { reinforcement of success }\end{array}$ & $30 \mathrm{~min}, 4$ times a week for 10 weeks \\
\hline Smith $1982^{35}$ & 66 healthy third grade pupils & $\begin{array}{l}\text { C: Regular activity } \\
\text { I: Games avoiding waiting for turn and inactivity } \\
\text { C: Free play }\end{array}$ & $30 \mathrm{~min}$, twice a week for 8 weeks \\
\hline
\end{tabular}

Table 3 Methodological quality of included studies

\begin{tabular}{|c|c|c|c|c|c|c|c|}
\hline Study & 1 & 2 & 3 & 4 & 5 & Risk of bias & Compliance \\
\hline Alpert $1990^{16}$ & + & + & + & + & + & Low & $98 \%$ \\
\hline Tuckman $1986^{37}$ & + & + & + & + & - & Moderate & Good according to the author \\
\hline Blvechardt $1994^{18}$ & $?$ & $?$ & + & + & + & Moderate & $85 \%$ in intervention group, $100 \%$ in control group \\
\hline Herman-Tofler $1998^{23}$ & - & + & - & + & + & Moderate & $100 \%$ \\
\hline MacMahon $1987^{27}$ & $?$ & + & + & + & $?$ & Moderate & Not reported \\
\hline Marsh $1988^{28}$ & - & + & + & + & - & Moderate & Good according to the author \\
\hline Salukon $1994^{34}$ & - & + & $?$ & + & + & Moderate & Not reported \\
\hline Smith $1982^{35}$ & - & + & + & + & - & Moderate & Good according to the author \\
\hline Smith $1984^{36}$ & $?$ & $?$ & + & + & + & Moderate & Not reported \\
\hline Basile $1995^{17}$ & + & $?$ & - & + & $?$ & High & Not reported \\
\hline Elstein $1977^{21}$ & - & - & - & + & + & High & Not reported \\
\hline MacMahon $1988^{15}$ & $?$ & + & + & - & $?$ & High & Not reported \\
\hline Munson $1988^{31}$ & - & - & + & + & - & High & Not reported \\
\hline Platzer $1976^{33}$ & $?$ & + & + & - & - & High & Good according to the author \\
\hline Boyd $1997^{19}$ & - & $?$ & + & $?$ & $?$ & High & Not reported \\
\hline Bruya $1977^{20}$ & - & $?$ & $?$ & $?$ & $?$ & High & Not reported \\
\hline Ford $1989^{22}$ & $?$ & $?$ & + & $?$ & $?$ & High & Not reported \\
\hline Hilyer $1979^{25}$ & $?$ & $?$ & + & $?$ & $?$ & High & Not reported \\
\hline Hilyer $1982^{24}$ & - & $?$ & + & - & $?$ & High & Not reported \\
\hline Luebke $1977^{26}$ & - & $?$ & + & $?$ & $?$ & High & Not reported \\
\hline McGowan $1974^{29}$ & $?$ & $?$ & $?$ & $?$ & $?$ & High & Not reported \\
\hline Munson $1985^{30}$ & - & - & + & $?$ & - & High & Not reported \\
\hline Percy $1981^{32}$ & $?$ & $?$ & $?$ & $?$ & $?$ & High & Not reported \\
\hline
\end{tabular}

Quality criteria: 1, allocation; 2, outcome assessment; 3, co-intervention; 4, losses to follow up; 5, intention to treat.

Categories: +, met; ?, unclear; -, not met.

Overall quality: 5 met $=$ low risk of bias; $3-4$ met $=$ moderate risk of bias; $<3$ met $=$ high risk of bias. 
Review: Exercise to improve self esteem in children and young people

Comparison: 01 Exercise only versus no treatment

Outcome: 01 Self esteem

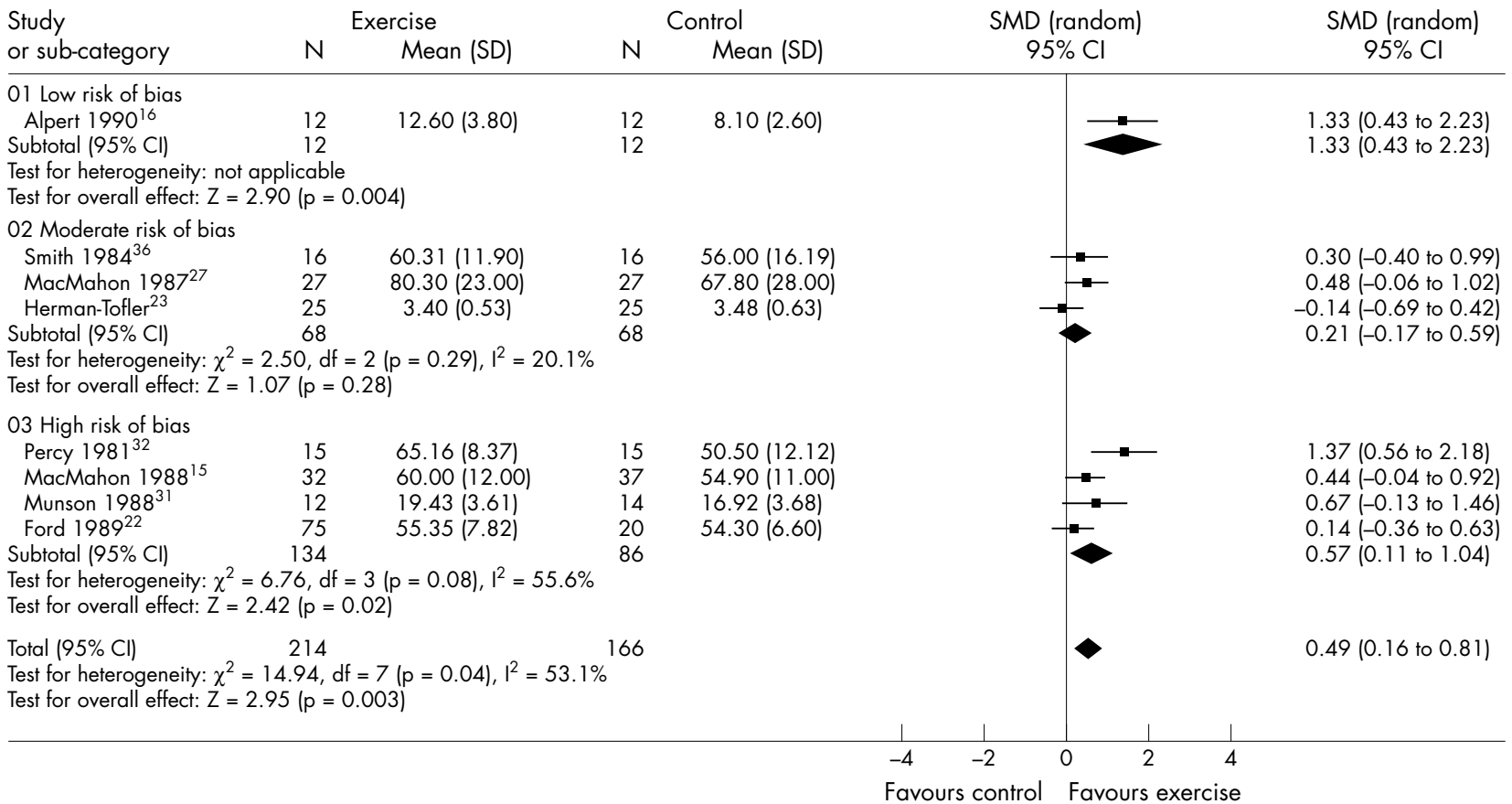

Figure 2 Meta-analysis of studies comparing exercise as a single intervention with no intervention. SMD, Standardised mean difference; Cl, confidence interval.

Because of the clinical and statistical heterogeneity, we performed sensitivity analyses. The only change in SMD of any possible important value was an increase in total SMD when the studies with children at risk were analysed separately. The effect size changed only marginally when weight lifting results, intervention with duration shorter than
10 weeks, or studies with differences in baseline measures of self esteem were excluded from the analysis. This is consistent with findings in many types of interventions or preventive programmes. ${ }^{38}$

Self esteem was reported by the children themselves on instruments that are well accepted and reasonably well tested

Review: $\quad$ Exercise to improve self esteem in children and young people

Comparison: 02 Exercise as part of a comprehensive intervention versus no treatment

Outcome: 01 Self esteem

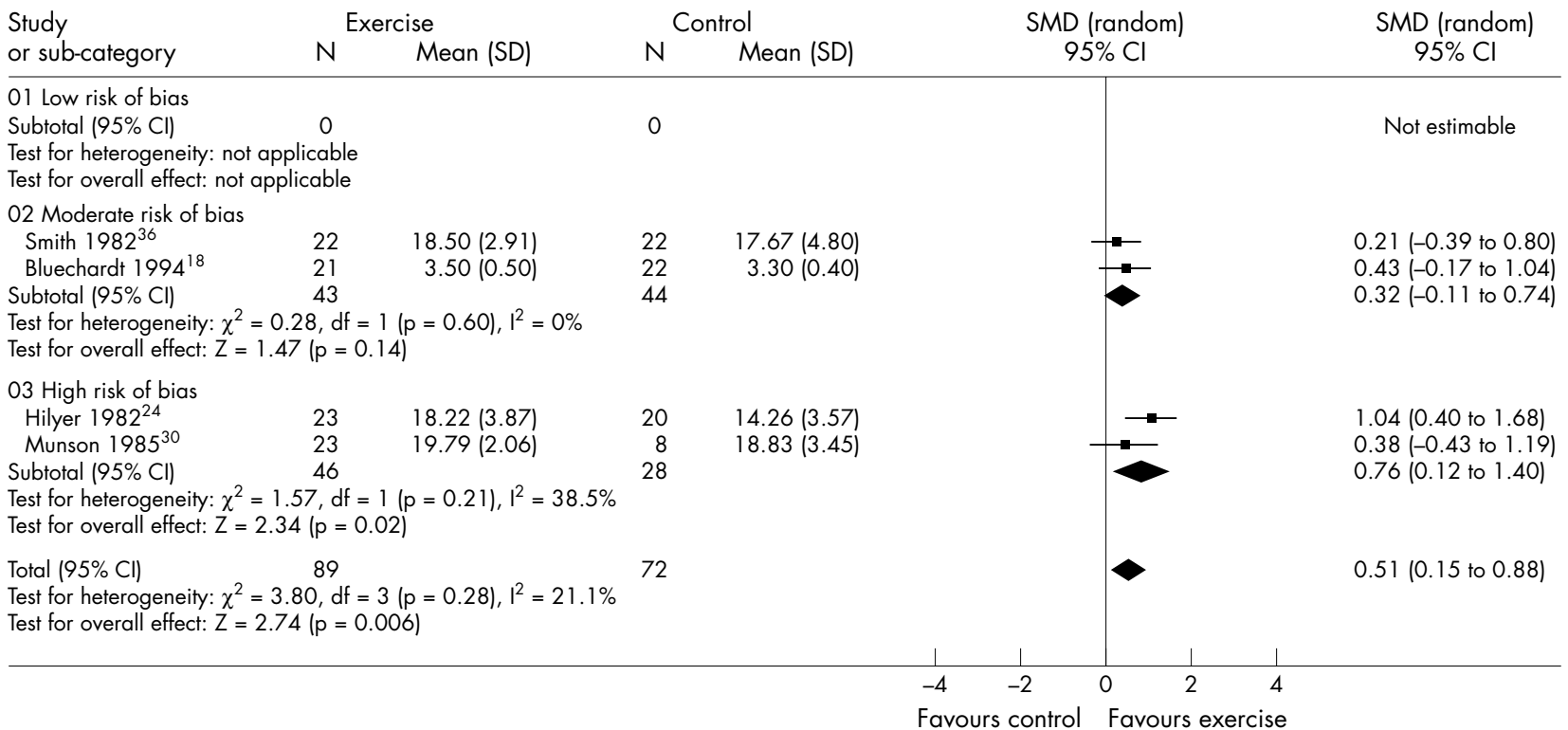

Figure 3 Meta-analysis of studies comparing exercise as a part of a comprehensive intervention with no intervention. SMD, Standardised mean difference; $\mathrm{Cl}$, confidence interval. 


\section{What is already known on this topic}

- There is a high incidence of mental problems among children and young people, and high self esteem may protect against such problems

- However, the effect of exercise on self esteem is largely unknown

for reliability and validity, with the possible exception of one study, where the quality of the method is not known..$^{33}$ There were no follow up data to show the extent to which the effects of programmes were maintained over longer periods of time, and none of the studies included factors indicating the degree of fun or enthusiasm among participants in the programmes. Whether the treatment effects were of clinical importance remains unclear. Some claims that a SMD of 0.5, in this case corresponding to a difference of self esteem of 5.5 on a $0-80$ scale, is a moderate effect. ${ }^{39}$ Still the important question of whether children with a difference in self esteem such as this have a different degree of robustness and protection against psychological problems remains unanswered.

All the included studies used more or less "ordinary activity" as control treatment. The comparisons are therefore not between exercise and complete physical inactivity. This means that the possible treatment effect of exercise might be underestimated in this review. The effect was also somewhat surprising considering the short duration of the interventions. The research included in this review cannot tell us anything about what kind of exercise might give positive effects, and in which setting.

The results of this review are limited because of the small number of participants in the included studies and the lack of studies with a low risk of bias. Despite the methodological problems referred to, the results indicate that exercise may be effective in improving self esteem in children and young people, at least in the short term and for children and young people at risk. As exercise has no known negative effects, and many positive effects, on somatic health, it is an important instrument in improving children's health.

This review reflects the need for rigorous research evaluating the effectiveness of exercise on children's self esteem. The field should be further investigated by well designed randomised controlled trials. There is a need for follow up data to show the extent to which the effects of programmes are maintained over time.

\section{ACKNOWLEDGEMENTS}

The study is partly funded by The Norwegian Fund for Post-Graduate Training in Physiotherapy. The researchers are independent from the fund.

\section{Authors' affiliations}

E Ekeland, Norwegian Physiotherapist Association, Oslo, Norway

F Heian, BUA, FSM Molde, Norway

K B Hagen, NRRK, Oslo, Norway

Competing interests: none declared

\section{REFERENCES}

1 Sonuga-Barke EJS, Thompson M, Stevenson J, et al. Patterns of behaviour problems among pre-school children. Psychol Med 1997;27:909-18.

2 Prior M. Childhood temperament. J Child Psychol Psychiatry 1992;33:249-79.

3 Garmezy N. Stress-resistant children: the search for protective factors. In: Stevenson JE, ed. Recent research in developmental psychopathology. Oxford/New York: Pergamon Press, 1985:213-33.
What this study adds

- Several low quality trials indicate that exercise has positive short term effects on self esteem in children and young people

- This study highlights the need for well designed, randomised controlled trials with long term follow up

4 Rutter M. Resilience in the face of adversity. Protective factors and resistance to psychiatric disorder. Br J Psychiatry 1985;36:459-571.

5 Haggerty RJ, Sherrod LR, Garmezy N, et al. Stress, risk and resilience in children and adolescents. Processes, mechanisms and interventions. Cambridge: Cambridge University Press, 1996.

6 Sonstroem RJ. Physical self-concept: assessment and external validity. Exerc Sport Sci Rev 1998;26:133-64.

7 Biddle S. Children, exercise and mental health. Int J Sport Psychol 1993;24:200-16.

8 Calfas KJ, Taylor WC. Effects of physical activity on psychological variables in adolescents. Pediatric Exercise Science 1994;6:406-23.

9 Mutrie N, Parfitt G. Physical activity and its link with mental, social and moral health in young people. In: Biddle S, Sallis J, Cavill N, eds. Young and active. London: Health Education Authority, 1998:49-68.

10 Fox KR. Physical education and the development of children's self esteem. In: Amstrong N, eds. New directions in physical education. 2. Towards a National Curriculum. Champaign, IL: Human Kinetics, 1992:33-54.

11 Gruber J. Physical activity and self esteem development in children: a metaanalysis. In: Stull G, Eckern H, eds. Effects of physical activity on children. Champaign, IL: Human Kinetics, 1986:330-48.

12 Ekeland E, Heian F, Hagen KB, et al. Exercise to improve self esteem in children and young people. Cochrane Database Syst Rev, 2004.Issue 1.CD003683.

13 In: Alderson P, Green S, Higgins JPT, eds. Cochrane Reviewers' Handbook 4. 2.2 (updated December 2003). Cochrane Library.Issue 1. Chichester: John Wiley \& Sons, Ltd, 2004.

14 Piers EV. Piers-Harris children's self-concept scale: revised manual. Los Angeles: Western Psychological Services, 1984.

15 MacMahon JR, Gross RT. Physical and psychological effects of aerobic exercise in delinquent adolescent males. Am J Dis Child 1988;142:1361-6

16 Alpert B, Field T, Goldstein S, et al. Aerobics enhances cardiovascular fitness and agility in preschoolers. Health Psychol 1990;9:48-56.

17 Basile VC, Motta RW, Allison DB. Antecedent exercise as a treatment for disruptive behavior: testing hypothesized mechanisms of action. Behavioral Interventions 1995; 10:119-40.

18 Bluechardt MHS. Effect of an after-school physical activity program on motor profiency and social skills of learning disabled children aged 8-11 years. PhD thesis, Department of Community Health, 1994.

19 Boyd KR, Hrycaiko DW. The effect of a physical activity intervention package on the self esteem of pre-adolescent and adolescent females. Adolescence 1997:32:693-708.

20 Bruya LD. Effect of selected movement skills on positive self-concept. Percept Mot Skills 1977;45:252-4

21 Elstein AE. Effects of physical education on the physical fitness, social adjustment, and self-concept of learning disabled students. Temple University, Ed D, Education, special, 1977.

22 Ford HT, Puckett JR, Blessing DL, et al. Effects of selected physical activities on health-related fitness and psychological well-being. Psychol Rep 1989;64:203-8.

23 Herman-Tofler L, Tuckman B. The effects of aerobic training on children's creativity, self-perception, and aerobic power. Child Adolesc Psychiatr Clin N Am 1998;7:773-90.

24 Hilyer JC, Wilson DG, Dillon C, et al. Physical fitness training and counseling as treatment for youthful offenders. J Couns Psychol 1982;29:292-303.

25 Hilyer JC Jr, Mitchell W. Effect of systematic physical fitness training combined with counseling on the self-concept of college students. J Couns Psychol 1979;26:427-36.

26 Luebke LLL. A comparison of the effects of two programs of elementary physical education on the self concept, knowledge of physical activity and physical fitness of third grade children. Dissertation, Marguette University, 1977.

27 MacMahon JR, Gross RT. Physical and psychological effects of aerobic exercise in boys with learning disabilities. J Dev Behav Pediatr 1987;8:274-7.

28 Marsh HW, Peart ND. Competitive and cooperative physical fitness training programs for girls: effects on physical fitness and multidimensional selfconcepts. Journal of Sport and Exercise Psychology 1988;10:390-407.

29 McGowan RW, Jarman BO, Pederssen DM. Effects of a competitive endurance training program on self-concept and peer approval. J Psychol 1974;86:57-60.

30 Munson WW, Baker SB, Lundegren HM. Strength training and leisure counseling as treatments for institutionalized juvenile delinquests. Adapted Physical Activity Quarterly 1985;2:65-75. 
31 Munson WW. Effects of leisure education versus physical activity or informal discussion on behaviorally disordered youth offenders. Adapted Physical Activity Quarterly 1988;5:305-17.

32 Percy LE, Dziuban CD, Martin JB. Analysis of effects of distance running on self-concepts of elementary students. Percept Mot Skills 1981;52:42.

33 Platzer WS. Effect of perceptual motor training on gross-motor skill and selfconcept of young children. Am J Occup Ther 1976;30:422-8.

34 Salokun SO. Positive change in self-concept as a function of improved performance in sports. Percept Mot Skills 1994:78:752-4.

35 Smith TL. Self-concepts and movement skills of third grade children after physical education programs. Percept Mot Skills 1982;54:1145-6.

36 Smith TP. An evaluation of the psychological effects of physical exercise on children. Diss Abstr Int 1984;7:2260.

37 Tuckman BW, Hinkle JS. An experimental study of the physical and psychological effects of aerobic exercise on schoolchildren. Health Psychol 1986;5:197-207.

38 Durlak JA, Wells AM. Primarly prevention mental health programs for children and adolescents: a meta-analytic review. Am J Community Psycho 1997:25: 115-52.

39 Cohen J. Statistical power analysis for the behavioral sciences, 2nd ed. Mahwah: Lawrence Erlbaum Associates, 1988.

\section{COMMENTARY}

It is useful to have a good quality systematic review to summarise the state of the evidence in this area. Low self esteem in children can lead to a range of psychosocial problems. In view of both the economic cost of other interventions (such as any kind of talking or play therapy) and the additional health benefits for children of taking more exercise, this is a useful intervention to consider. It is hoped that the call for more high quality randomised controlled trials to assess effectiveness will be taken up by research commissioners.

E Coren

UK Cochrane Centre; ecoren@cochrane.co.uk

\section{$\mathrm{ECHO}$}

\section{Warming up lowers pivotal injuries in youth sports}

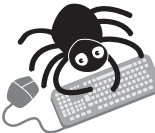

Please visit the British Journal of Sports Medicine website [www. bjsportmed. com] for a link to the full text of this article. structured warm up programme should be part of all youth sports to save serious knee and ankle injuries, say researchers in sports trauma, based on a cluster randomised control trial.

This is the first time a large enough trial has been carried out to show this definitely. The researchers are confident that their findings in handball players will apply to other sports with similar moves and similar patterns and mechanisms of injury and that players of all levels would benefit.

The risks of injuries to legs and of acute knee and ankle injuries were drastically reduced - by half or more-in handball clubs randomised to receive the programme than the control clubs whose members followed their usual training regime. The rate ratio of acute injuries overall and knee or ankle injuries also dropped significantly in matches.

The trial included 1837 players aged 15-17 years in federation handball clubs in central and eastern Norway, randomly assigned to the programme or to act as controls. The two groups were matched by region, playing level, sex, and number of players. The Oslo Sports Trauma Research Centre and Norway's Handball Federation devised the programme to foster awareness and control in movements of the knee and ankles. It was used the first 15 consecutive training sessions, then once a week throughout the league (eight months).

Sports injuries count for up to a fifth of acute emergency injuries in Scandinavia. Most are knee and ankle injuries, the most serious being commonest among adolescents in sports that entail pivoting movements.

A Olsen O-E, et al. BMJ 2005;330:449-452. 